\title{
Preliminary results of a physiologically based treatment of amblyopia
}

\author{
FERGUS W. CAMPBELL, ROBERT F. HESS, PETER G. WATSON, AND \\ RUTH BANKS \\ From the Physiological Laboratory and the Department of Ophthalmology, Addenbrooke's Hospital, \\ Cambridge
}

SUMMARY An apparatus has been developed in which high-contrast square-wave gratings are rotated in front of the amblyopic eye while the child is performing some task requiring visual concentration. In the course of three 7 -minute treatments $73 \%$ of patients treated achieved $6 / 12$ or better; $75 \%$ of these patients had previously undertaken conventional or minimal occlusion.

Over the past decade neurophysiological experiments have demonstrated that the animal visual system is highly tuned for spatial frequency and orientation (Campbell et al., 1968; Campbell et al., 1969; Maffei and Fiorentini, 1973; Robson, 1975). Independent psychophysical experiments on man (for review see Campbell, 1974) substantiate that both spatial frequency and orientation are 'des pudels Kern' (Granit, 1974; 1977) for human vision.

Interest in amblyopia has recently been revived among physiologists because an understanding of its neural basis may have an important bearing on development theories of sensory function. Although this recent approach (Campbell, 1974) has been usefully applied to the investigation of the neural abnormality in amblyopia (Gstalder and Green, 1971; Levi and Harwerth, 1977; Hess and Howell, 1977) it has not yet been applied to the treatment of amblyopia.

The main rationale of amblyopia therapy has remained, with a few minor exceptions, unchanged for over 200 years (de Buffon, 1746). Although more recently pleoptics has developed in an attempt to centralise fixation, occlusion therapy in one form or another (for review see Hess, 1971) is still the most widely used and successful technique. Conventional full-time occlusion of the normal eye in patients who have macular fixation improves visual acuity to $6 / 12$ or better in $88 \%$ (Catford, 1967). This figure falls to between 40 and $60 \%$ in patients who have eccentric fixation (Dayson, 1968; Pope, 1971; Olivier and Nawratzki, 1971; Piligrim and

Address for reprints: Mr Peter G. Watson, 17 Adams Road, Cambridge CB3 9AD
Turner, 1974). Full-time conventional occlusion, although it does sometimes produce dramatic and rapid improvement (Chavasse, 1939), usually has to be continued for between 3 and 18 months to achieve this level of improvement. It is a tedious and educationally disruptive technique, and its failure rate is high.

As an alternative to total occlusion we have recommended occlusion of the good eye every day for only 20 minutes while intensive close work was being undertaken; this achieved much better cooperation from the mother. With this treatment $83 \%$ of children improved their acuity to $6 / 12$ or better $(45 \%$ to $6 / 9)$ in the amblyopic eye. It produced an improvement in acuity disproportionate to its short duration, but it did take an average of 13 weeks to achieve this.

The surprising finding of the relative efficacy of 'minimal occlusion' led one of us (FWC) to consider what would be the most effective stimulus for the visual system during this limited period. Recent neurophysiological findings in animals and man (Robson, 1976; Campbell, 1974) suggest that to activate fully the entire population of visual neurones in the visual cortex a range of different spatial frequency gratings covering all orientations should be used. These criteria are best met by using a repetitive grating pattern with sharp luminance edges slowly rotating through $180^{\circ}$. This stimulus, which is based on current neurophysiological findings, was constructed (Banks et al., 1978) and is being tested on a wide selection of amblyopic children. The preliminary findings, which are reported here, suggest that this new approach improves vision in the amblyopic eye much faster and more completely than any other technique. 


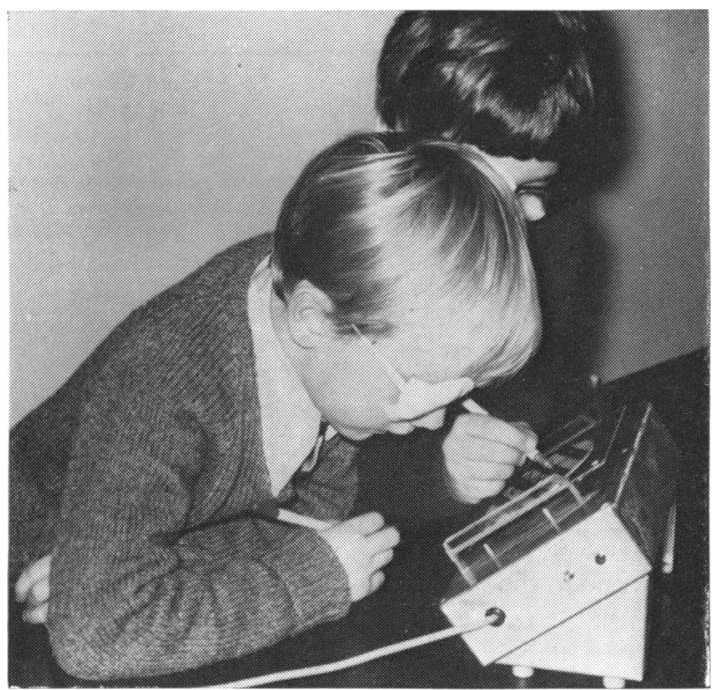

Fig. 1 The grating treatment device in use

The simplicity and low cost of the method has encouraged us to publish these early results so that the treatment can be assessed on a much greater number of children and adults.

\section{Patients and methods}

Treatment consists in viewing an apparatus on which any one of a selection of high-contrast square-wave gratings are rotated slowly at 1 revolution per minute behind a transparent cover on which drawing games can be played. Occlusion was used (only during the test) to limit vision to the amblyopic eye. If possible, 2 patients of equal age and intelligence were seated side by side in front of the apparatus with the non-amblyopic eye occluded (Fig. 1). The intended distance from the eye of the patient to the grating disc was $57 \mathrm{~cm}$, but almost all the children worked closer than this. If only 1 patient was being treated, the orthoptist acted as the opponent in the game for the duration of the treatment.

The length of treatment was standardised so that the patient was observing the gratings for 7 minutes. The selected grating to be used was placed on the turntable; the Perspex plate was placed over this, and the patients were given drawing pens. The patients were then instructed, according to age and abilities, to play 'noughts and crosses', 'hangman', 'squares', or 'boxes', or to draw pictures, while the grating was rotating under the Perspex plate. This procedure forced the child to attend to the underlying stimulus.

All patients had a full ophthalmological examination, cycloplegic refraction, and orthoptic assessment, although it was not possible to fully assess binocular functions in all of them. The majority of children tested $(75 \%)$ had previously undertaken partial or constant total occlusion, which had at best been only partially effective. Before any treatment was administered, visual acuity was assessed by the Snellen or linear Sheridan Gardiner optotypes and Sheridan single optotypes at 6 and $0.33 \mathrm{~m}$. In those patients who had been recently accepted for treatment contrast thresholds for both a low and medium spatial frequency grating were assessed with simplified clinical plates.

These plates were circular and consisted of a sine grating each at a different contrast level near threshold. Each plate was presented to the child firstly at the highest contrast, and the child indicated its orientation. The contrast at which this task could not be performed was taken as the threshold. Normal and amblyopic eyes were tested with this technique for a low as well as a medium frequency grating.

Fig. 2 Range of grating stimuli

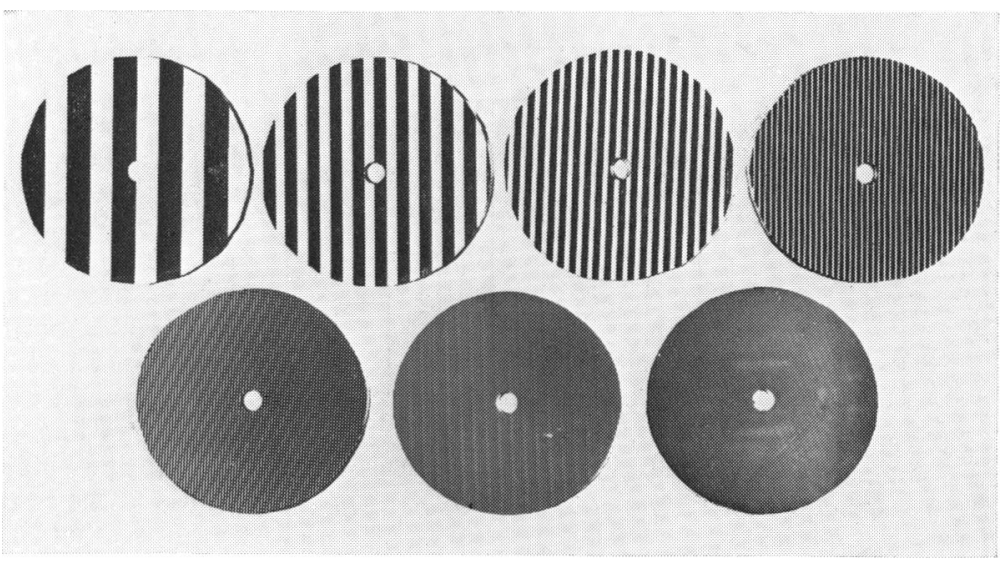
used 
More recently the information derived from this simple and quick clinical test was used to select the initial spatial frequency used in the subsequent treatment and to assess (along with acuity measurements) its effectiveness. For example, if this test indicated that the amblyopic abnormality was limited to only medium to high frequencies (Gstalder and Green, 1971; Hess and Howell, 1977), then only spatial frequencies in this range were selected for treatment and subsequent assessment. On the other hand if the amblyopic abnormality extended to include low as well as high frequency gratings (Hess and Howell, 1977), a low spatial frequency grating was selected initially. Fixation of the amblyopic eye was assessed by projection ophthalmoscopy.

In the first group of patients all the gratings were used in sequence within a 7 minute treatment period, the treatment starting with a low frequency $(0.5$ $\mathrm{c} / \mathrm{deg})$ and working to the highest $(32 \mathrm{c} / \mathrm{deg})$. The abbreviated contrast threshold technique, which has already been discussed, was later adopted and found to be also satisfactory. If low frequencies were found to be abnormal, treatment was started at $0.5 \mathrm{c} / \mathrm{deg}$, whereas if only medium to high frequencies were found to be abnormal treatment was started at 8 or $16 \mathrm{c} / \mathrm{deg}$. In most patients at least 2 gratings were used during each 7 -minute treatment period. In certain patients an unstructured disc (with no grating) was used as a control. After treatment linear Snellen and Sheridan Gardiner acuities and Sheridan Gardiner single optotypes were reassessed at 6 and $0.33 \mathrm{~m}$, and contrast threshold was also reassessed. The visual acuity after treatment was always assessed, but if concentration was suspect it was not assessed before treatment began.

The patient was then sent home with specific instructions not to occlude the non-amblyopic eye. The majority of patients were treated at weekly intervals. A few were treated at home on a daily

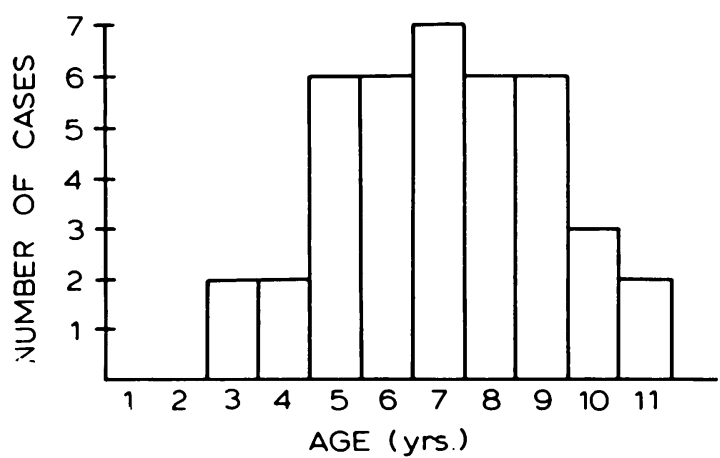

Fig. 3 Age distribution of the 50 children treated with the grating stimulus
Table 1

\begin{tabular}{|c|c|c|c|c|c|c|}
\hline \multirow[b]{3}{*}{ Without vertical imbalance } & \multirow{2}{*}{\multicolumn{3}{|c|}{$\begin{array}{l}\begin{array}{l}\text { Strabismic } \\
\text { amblyopia }\end{array} \\
\text { Nystagmoid } \\
\text { fixation movements }\end{array}$}} & \multirow{2}{*}{\multicolumn{3}{|c|}{$\begin{array}{l}\text { Anisometropic } \\
\text { amblyopia }\end{array}$}} \\
\hline & & & & & & \\
\hline & $\begin{array}{c}\text { Yes } \\
7\end{array}$ & $\begin{array}{c}\mathrm{No}_{4} \\
\text {. }\end{array}$ & $\begin{array}{l}\text { Total } \\
11\end{array}$ & $\begin{array}{l}\text { Yes } \\
2\end{array}$ & $\begin{array}{l}\text { No } \\
7\end{array}$ & $\begin{array}{l}\text { Total } \\
9\end{array}$ \\
\hline With vertical imbalance & 19 & 9 & 28 & - & 1 & 1 \\
\hline Astigmatisms-both eyes & s 8 & 5 & 13 & - & 3 & 3 \\
\hline Amblyopic eye & 7 & 5 & 12 & 1 & 2 & 3 \\
\hline Eccentric fixation & 13 & 6 & 19 & - & - & - \\
\hline Anisometropia & 16 & 10 & 26 & 2 & 8 & 10 \\
\hline
\end{tabular}

basis under the supervision of their parents if they were unable to attend regularly.

Two patients attended the clinic daily for treatment. The treatment was continued until there was no further improvement in visual acuity or until the visual acuity was equalised in both eyes. After this the visual acuity and binocular functions were reassessed at 2- or 4-weekly intervals to ensure that no deterioration occurred.

\section{Results}

Of the 50 patients treated with this apparatus some improvement in visual acuity occurred in all but 2 , some better for near vision than distance and vice versa. Improvement occurred regardless of whether the patient had strabismic or anisometropic amblyopia. Two patients who were thought to have deprivation amblyopia both improved, but one had anisometropia and the other had anisometropia together with a squint. The former has been included in the anisometropic group and the latter in the strabismic group. It was noted that the majority of patients had nystagmoid movements in the amblyopic eye and also the crowding phenomenon. These patients did not respond so well to treatment. Fig. 3 gives the age distribution of the patients who were treated. Table 1 classifies the patients according to the type of deviation, associated ametropia, presence of nystagmoid movements, and eccentric fixation.

The results before and after treatment as assessed by visual acuity for distance and near are displayed in Figs. 4-6. In each of these figures acuity before treatment is plotted against acuity after treatment for distance $(\triangle)$ and near $(\Delta)$ acuity. Patients who have not been previously treated are also indicated (ब). According to this method of display the oblique sloping lines indicate no improvement after treatment and the extent to which the data are displaced upwards, that is towards the dashed line (6/6), 
Fig. 4 Improvement of distance (unfilled symbols) and near (filled symbols) acuity after the first 7 minutes of grating treatment. Enclosed symbols represent patients who have not had previous treatment. Upward displacement represents acuity improvement from treatment whereas data falling on the sloping lines represent no acuity change.

AFTER FIRST TREATMENT

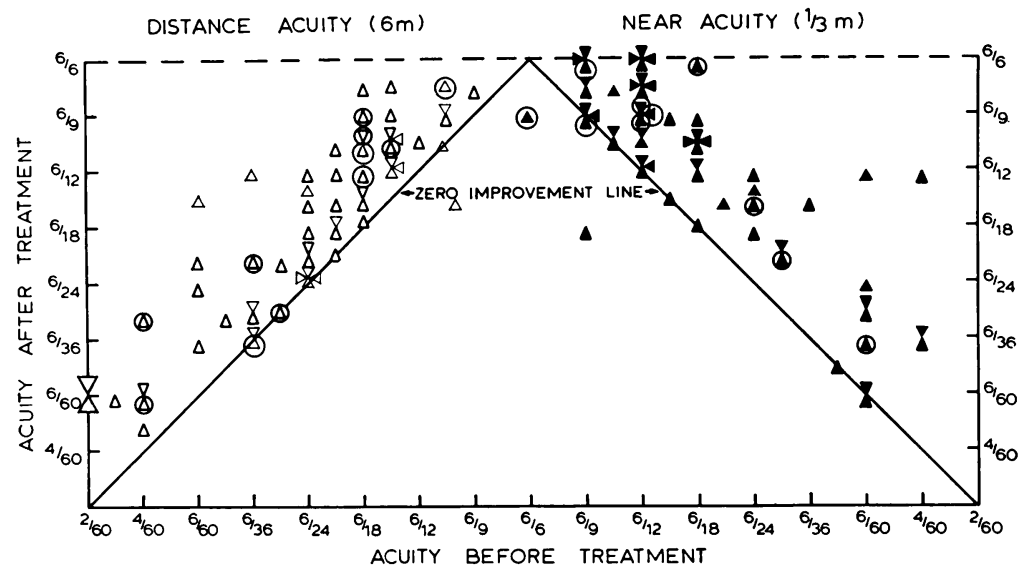

AFTER SECOND TREATMENT

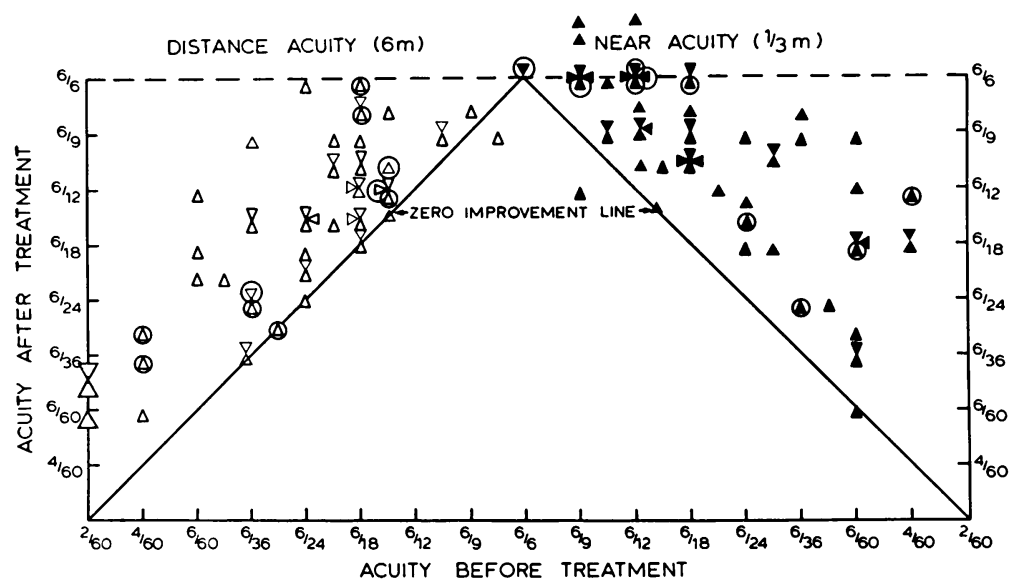

Fig. 5 Improvement of distance (unfilled symbols) and near (filled symbols) acuity after the 7-minute treatment. Enclosed symbols represent patients who had not previously undertaken orthoptic treatment. Improvement of acuity (upward displacement) is with reference to acuity before any treatment (sloping line)

Fig. 6 Improvement of distance (unfilled symbols) and near (filled symbols) acuity after the third 7-minute treatment.

Enclosed symbols represent patients who had not previously undertaken orpthoptic treatment. Improvement of acuity (upward displacement) is with reference to acuity before any treatment (sloping lines)

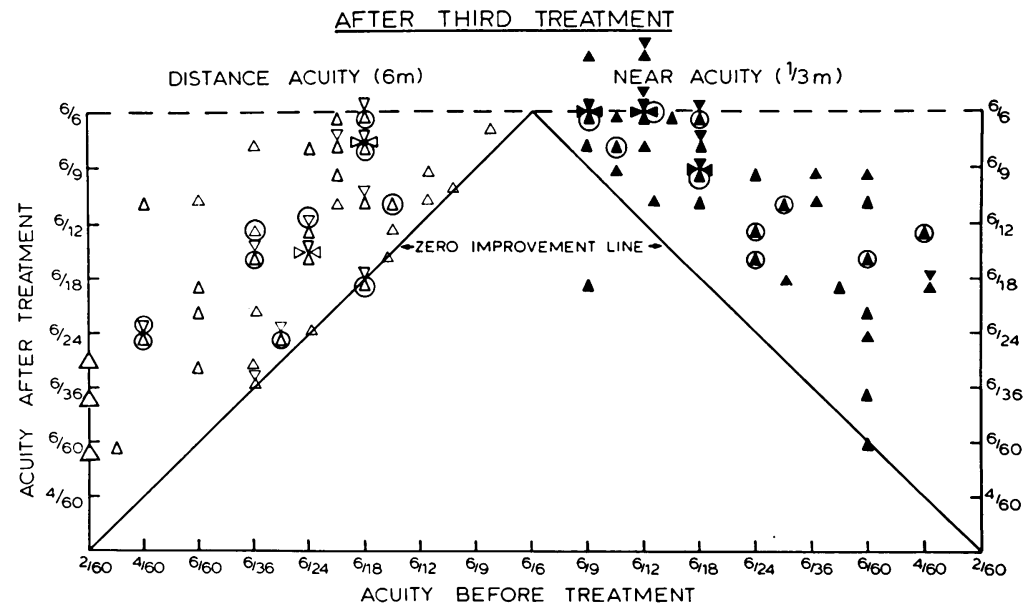


indicates the magnitude of the improvement with treatment compared with the original acuity before treatment. The results are displayed for the first 3 treatment sessions, each lasting 7 minutes. The data could have been displayed on other axes to amplify the large absolute improvement for low acuities, but it was decided to use this arbitrary but clinically familiar scale.

The results indicate that in the majority of cases acuity improved at both distance and near. As expected, cases which had not previously been treated with occlusion in one form or another improved more rapidly and to a greater extent with treatment. Improvement in acuity was maintained between treatments, and it is clear from the results that acuity improves in most cases across the 3 treatment sessions. After the third treatment session only 3 patients $(7 \%)$ had failed to respond to treatment. The number of treatments required to achieve the maximum level of acuity by this new method varies considerably between patients. Even though some cases are slower than others to improve, the convenience and brevity of the treatment will still be economic in clinical time.

So far 22 patients have completed the treatment. The average number of treatments required to achieve the maximum visual acuity as 4 (see Table 2). Regression of visual acuity after treatment has been discontinued has never been more than one Snellen line and then only at $6 \mathrm{~m}$. These patients have almost invariably had nystagmoid jerks of the amblyopic eye. The contrast thresholds for a low and medium frequency grating have remained stable even though letter acuity has varied.

The contrast threshold results also indicated improvement with treatment for both low and high spatial frequencies, which are known to be abnormal in this condition (Hess and Howell, 1977). In some cases contrast thresholds improved even though acuity was not measurably altered, indicating the more sensitive nature of the former measurement (Campbell and Green, 1965; Hess and Garner, 1977). In such cases subsequent treatments resulted in acuity as well as contrast threshold improvement.

To illustrate further that this new treatment technique improves overall visual function as well as acuity the contrast sensitivity function was measured in the laboratory for 1 patient aged 10 years before and after one 7-minute treatment session. Both the normal and fellow amblyope eyes were tested to ensure improvement did not result from experience with the technique. These results are displayed in Fig. 7 as spatial frequency versus contrast sensitivity for the normal $(\nabla)$ and fellow amblyopic $(\Delta)$ before (unfilled symbols) and after treatment (filled symbols). The results show that
Table 2 Completed treatments

\begin{tabular}{|c|c|c|c|c|}
\hline Case No. & $\begin{array}{l}\text { Age } \\
\text { (years) }\end{array}$ & $\begin{array}{l}\text { Initial } \\
\text { visual acuity }\end{array}$ & $\begin{array}{l}\text { Final } \\
\text { visual acuity }\end{array}$ & $\begin{array}{l}\text { No. of } 7 \text {-minute } \\
\text { treatments required }\end{array}$ \\
\hline 1 & 10 & $4 / 60$ & $6 / 60 \times 1$ & 40 \\
\hline 2 & $45 / 12$ & $6 / 18$ & $6 / 6$ & 4 \\
\hline 3 & 8 & $6 / 24$ & $6 / 9+$ & 6 \\
\hline 4 & $610 / 12$ & $6 / 18$ & $6 / 9+$ & 3 \\
\hline 5 & $86 / 12$ & $6 / 24$ & $6 / 18$ & 4 \\
\hline 6 & $510 / 12$ & $6 / 36$ & $6 / 24$ & 2 \\
\hline 7 & $76 / 12$ & $6 / 18+$ & $6 / 9+$ & 3 \\
\hline 8 & 9 & $6 / 36+$ & $6 / 9$ & 26 \\
\hline 9 & 9 & $6 / 12$ & $6 / 12+$ & 2 \\
\hline 10 & $96 / 12$ & $3 / 60$ & $6 / 60$ & 1 \\
\hline 11 & $93 / 12$ & $6 / 60$ & $6 / 36$ & 2 \\
\hline 12 & 12 & $6 / 60$ & $6 / 36+$ & 3 \\
\hline 13 & $86 / 12$ & $6 / 9$ & $6 / 6-$ & 1 \\
\hline 14 & 10 & $6 / 60+$ & $6 / 18$ & 4 \\
\hline 15 & $46 / 12$ & $6 / 24+$ & $6 / 6$ & 3 \\
\hline 16 & $66 / 12$ & $6 / 18$ & $6 / 9+$ & 7 \\
\hline 17 & $79 / 12$ & $6 / 24+$ & $6 / 6$ & 2 \\
\hline 18 & 9 & $6 / 24+$ & $6 / 9$ & 3 \\
\hline 19 & $68 / 12$ & $6 / 18+$ & $6 / 6$ & 8 \\
\hline 20 & $102 / 12$ & $6 / 24$ & $6 / 18+$ & 3 \\
\hline 21 & 9 & $4 / 60$ & $6 / 6$ & 10 \\
\hline 22 & $73 / 12$ & $6 / 18+$ & $6 / 9$ & 5 \\
\hline
\end{tabular}

the contrast sensitivity abnormality for this patient is confined to only high spatial frequencies (type I amblyopia, see classification of Hess and Howell, 1977). The results show that treatment resulted in a substantial improvement in high-frequency contrast sensitivity of half a log unit, and grating acuity (extrapolation to axis) improved from 20 to $30 \mathrm{c} / \mathrm{deg}$. Letter acuity improved from $6 / 24$ to $6 / 9$ for distance and from $6 / 18$ to $6 / 9$ for near vision. Since the normal eye acting as a control did not alter when contrast sensitivity was retested, it can be concluded that the improvement for the amblyopic eye resulted from treatment. Such visual improvement is dramatic when it is realised that treatment lasted for only 7 minutes and that contrast thresholds as well as acuity improved.

Figs. 8-10 represent three amblyopic patients chosen to represent the range of response from treatment. In the first case (Fig. 8) acuity for distance 
Fig. 7 Contrast sensitivity functions are compared for the normal $(\mathrm{Z})$ and fellow amblyopic eye $(\Delta)$ before and after $(0 ; \bullet)$ 7 minutes of treatment using gratings. Standard errors were never larger than the symbol size used

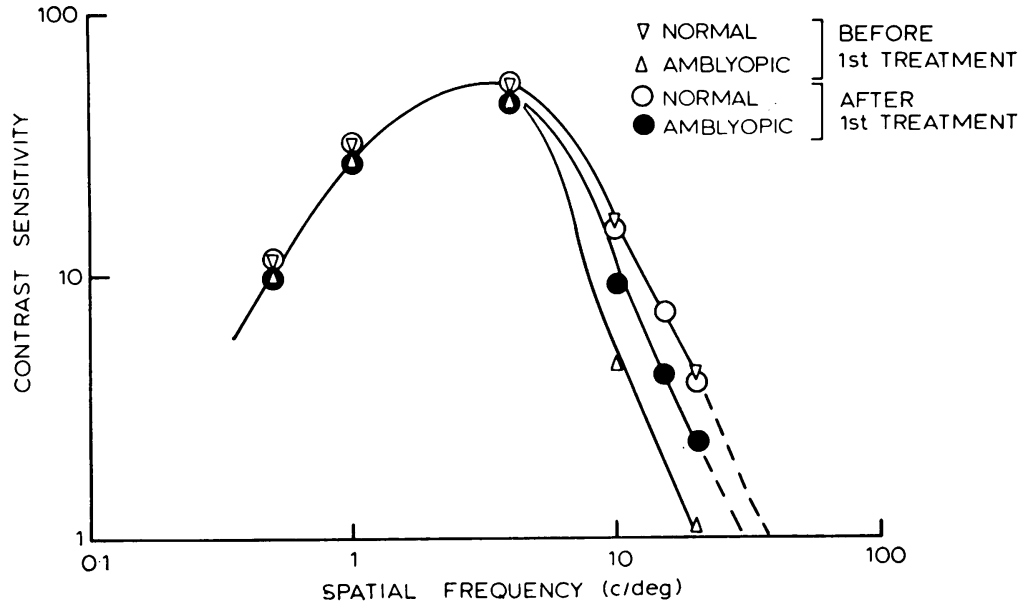

and near vision improved from $4 / 60$ to $6 / 6$ after 10 treatment sessions (each of 7 minutes) spread over 21 days; this represents the largest magnitude improvement of any patient so far studied. Fig. 9 illustrates one of the most unsuccessful amblyopic patients in that acuity improved only from 6/36 (distance) and 6/24+ (near) to 6/12+ after 26 treatment sessions. The child was treated by the mother at home, and the sparsity of data is due to the infrequent visits for hospital assessment. One of the most rapid treatment effects is illustrated in Fig. 10, in which acuity of $6 / 18$ improved to $6 / 6$ after only 3 treatment sessions. The full case records for these three amblyopic cases are given elsewhere (Banks et al., 1978).

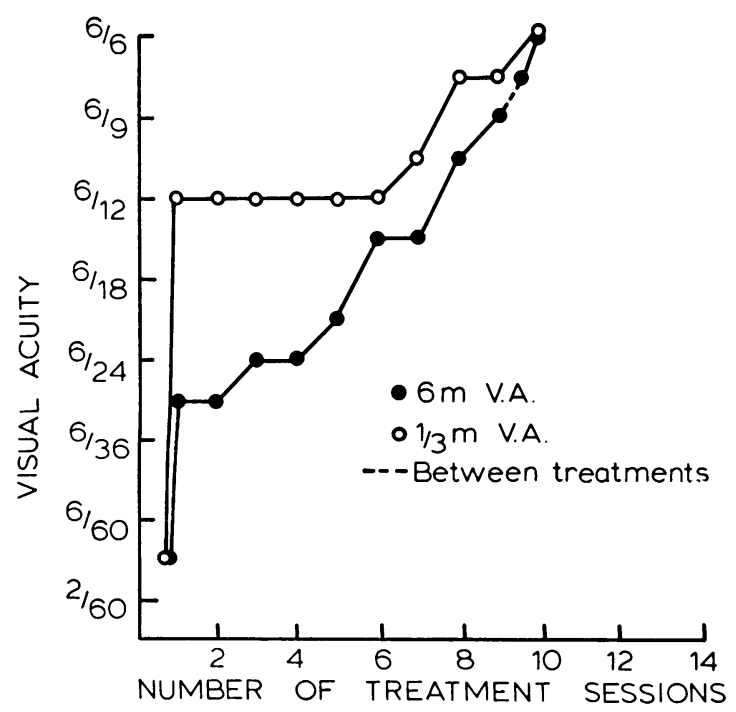

Fig. 8 Case 1 , age 9 years

\section{Discussion}

While we consider this method to be a highly significant advance in the treatment of strabismic and anisometropic amblyopia, we believe there is a considerable danger (because of the treatment's effectiveness) that intractible diplopia could be induced, with all its disastrous and possibly medicolegal consequences if the treatment is applied inappropriately. Until more is known about the reason for the improvement in vision we consider that the use of this instrument should be confined to hospitals and clinics under strict clinical supervision.

The results of this study are important from 2 separate standpoints. Firstly, they indicate that this simplified and clinically convenient procedure is as effective as, if not more effective than, the currently used procedures, which are lengthy and psychologically disturbing. Secondly, such a result could have important underlying physiological implications, especially as in some cases the acuity and contrast sensitivity changes are large and extremely rapid.

The time course of these improvements and the age at which they occur do not tally in any simple manner with the numerous studies of the "critical period' for visual deprivation in cats and monkeys (Wiesel and Hubel, 1963a, b; 1965a, b; van Noorden et al., 1970; Blakemore and Van Sluyters, 1974). It is very unlikely that the amblyopes that we have studied have actually lost neurones which subsequently regenerate with treatment. It seems more probable, in the light of the treatment time course, that neurones in amblyopia have reduced function (Hess, 1977), resulting in depressed contrast sensitivity (Hess and Howell, 1977; see also Fig. 7). 


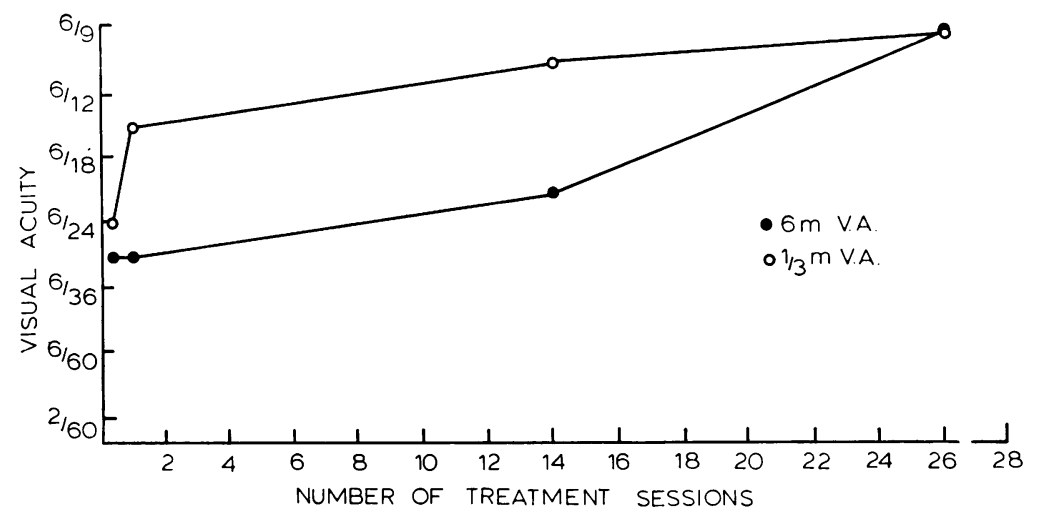

Fig. 9 Case 2, age 9 years

Yet a further possibility which has previously not been considered is that each neurone responds normally to its optimal stimulus but they do not work together as in normal vision, resulting in a scrambling of the transmitted signal. An analogy might be viewing a distant scene in the hot shimmering air of the desert, except of course it would not be moving and resemble that of a still photograph taken of the scene. Indeed we have made some preliminary observations on adult amblyopes whose contrast sensitivity measured with sine wave gratings is equal in the 2 eyes. However, the amblyope does not 'see' a regular periodic grating like the normal eye, for they describe it as being 'broken up' and 'jumbled' (Campbell et al., in preparation). Neurophysiologists have not des-

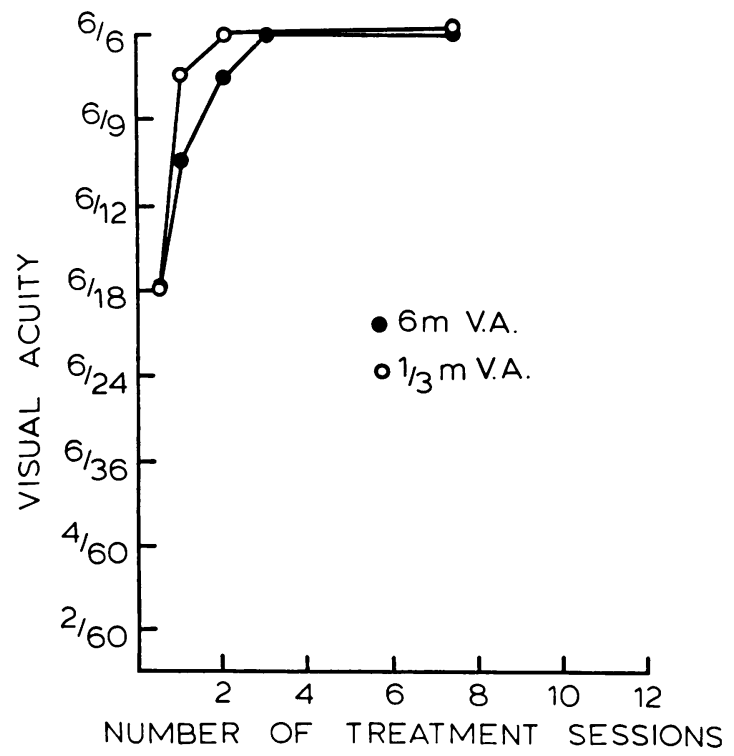

Fig. 10 Case 3 , age $6 \frac{1}{2}$ years cribed such an anomaly, but this is because they have not looked for phase and orientational scrambling in the visual system of deprived animals.

A further analogy more familiar to the reader might be as follows. Imagine taking a short-duration flash photograph of an optotype test chart lying on the pebbles of a clear shallow stream. The resulting photograph would show multiple and complex (phase) distortions due to the rippling on the surface of the water. The resollable detail on the test type would be much less, though the integrated contrast between the black and white segments would remain constant. In other words, the amplitude information is maintained but the positional or phase information is corrupted.

In the conventional treatment of amblyopia by occlusion plenty of images are falling on the retina of the amblyopic eye as the child goes about its daily life; yet this input, while it improves vision slightly, does so very slowly and inadequately. What then is so special about a rotating grating? Adriana Fiorentini, of the University of Pisa, pointed out to us that nothing in the normal world rotates in this manner, nor does any movement of the body stimulate such movement on the retina. Perhaps the amblyopic visual system requires the whole gamut of motion?

We thank Mrs Fay Barnett and Miss Claire Smith, orthoptists of Addenbrooke's Hospital, and Dave Burr, of the physiological laboratory, for their help and discussion which contributed to this project. As always we are indebted to Clive Hood, without whose assistance this project would never have got off the ground. F. R. Hess was supported by a Rotary International Fellowship. We also wish to thank J. E. Cairns, FRCS, and J. Keast-Butler, FRCS, for providing suitable patients.

\section{References}

Banks, R. V., Campbell, F. W., and Hood, C. (1978). A neurophysiological approach to the treatment of 
amblyopia. Journal of Physiology, 275, 16-17.

Banks, R. V., Campbell, F. W., Hess, R. F., and Watson, P. G. (1978). A new treatment for amblyopia. British Journal of Orthoptics, 35, 1-12.

Blakemore, C., and Van Sluyters, R. (1974). Reversal of the physiological effects of monocular deprivation in kittens. Further evidence for a sensitive period. Journal of Physiology, 237, 195-216.

Campbell, F. W. (1974). The transmission of spatial information through the visual system. The Neurosciences Third Study Program, pp. 95-103. MIT Press: London.

Campbell, F. W., Cleland, B., Cooper, G. F., and EnrothCugell, C. (1968). The angular selectivity of visual cortical cells to moving gratings. Journal of Physiology, 198, 237-250.

Campbell, F. W., Cooper, G. F., and Enroth-Cugell, C. (1969). The spatial selectivity of visual cells of the cat. Journal of Physiology, 203, 223-235.

Campbell, F. W., and Green, D. G. (1965). Monocular versus binocular visual acuity. Nature, 208, 191-192.

Catford, G. V. (1967). Transactions of the Ophthalmological Societies of the United Kingdom, 87, 179.

Chavasse, F. B. (1939) .Worth's Squint, 7th edn., p. 437. Balliére, Tindall \& Cox: London.

Dayson, A. (1968). Five year survey of the use of occlusion in the treatment of eccentric fixation. British Journal of Orthoptics, 25, 66.

Buffon, G. Leclerc de (1746). Dissertation sur les causes du strabisme, ou des yeux louches. Mémoires de l'Académie Royale des Sciences (Paris), pp. 231-248.

Granit, R. (1974). The concept of receptive field. Documenta Ophthalmological Proceedings Series XIth ISCERG Symposium, p. 3.

Granit, R. (1977). The purposive brain, p. 130. MIT Press: Cambridge, Mass.

Gstalder, R. J., and Green, D. G. (1971). Laser interference acuity in amblyopia. Journal of Pediatric Ophthalmology, 8, 251-255.

Hess, R. F. (1971). An appraisal of the prognosis and treatment for a functional curve of horizontal concomitant strabismus. Australian Journal of Optometry, 54, 129-148.

Hess, R. F., and Garner, L. F. (1977). The effect of corneal edema on visual function. Investigative Ophthalmology, 16, 5-13.

Hess, R. F. (1977). Assessment of stimulus field size for strabismic amblyopes. American Journal of Optometry and Physiological Optics, 54, 292-299.

Hess, R. F., and Howell, E. R. (1977). The threshold contrast sensitivity function in strabismic amblyopia: evidence for a two type classification. Vision Research, 17, 1049-1057.

Levi, D. M., and Harwerth, R. S. (1977). Spatio-temporal interactions in anisometropic and strabismic amblyopia. Investigative Ophthalmology, 16, 90-95.

Maffei, L., and Fiorentini, A. (1973). The visual cortex as a spatial frequency analyser. Vision Research, 13, 1255-1267.

Oliver, M., and Nawratzki, I. (1971). Screening of preschool children for ocular anomalies. II. Amblyopia: Prevalence and therapeutic results at different ages. British Journal of Ophthalmology, 55, 467.

Piligrim, A., and Turner, S. (1974). A survey of cases of eccentric fixation in children up to 10 years of age, seen during the last 10 years. British Journal of Orthoptics, 31, 59.

Pope, L. G. (1971). Treatment of eccentric fixation without occlusion. British Journal of Orthoptics, 28, 77.

Robson, J. G. (1975). Receptive fields: Neural representation of the spatial and intensive attributes of the visual image. Handbook of Perception, vol. 5, p. 81. Edited by E. C. Carterette and M. P. Friedman. Academic Press: London. van Noorden, G. K., Dowling, J. E., and Ferguson, D. C. (1970). Experimental amblyopia in monkeys. American Archives of Ophthalmology, 84, 206-214.

Wiesel, T. N., and Hubel, D. H. (1963a). Effects of visual deprivation on morphology and physiology of cells in the cat lateral geniculate body. Journal of Neurophysiology, 26, 978-993.

Wiesel, T. N., and Hubel, D. H. (1963b). Single cell responses in striate cortex of kittens deprived of vision in one eye. Journal of Neurophysiology, 26, 1003-1017.

Wiesel, T. N., and Hubel, D. H. (1965a). Comparison of the effects of unilateral and bilateral eye closure on cortical unit responses in kittens. Journal of Neurophysiology, 28, 1029-1040.

Wiesel, T. N., and Hubel, D. H. (1965b). Extent of recovery from effects of visual deprivation in kittens. Journal of Neurophysiology, 28, 1040-1060. 